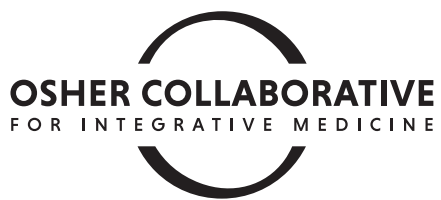

\title{
Integrative Medicine Is a Good Prescription for Patients and Planet
}

\author{
Aterah Z. Nusrat, MSc, DIC, Iman Majd, MD, MS, EAMP/LAc, ${ }^{2}$ and Peter M. Wayne, $\mathrm{PhD}^{1}$
}

Editor's Note: This is the sixth commentary through the JACM column partnership with the Osher Collaborative for Integrative Medicine. Our goal with these commentaries is to stimulate critical conversations in the field through perspectives from the leaders of the Collaborative's seven prominent academically-based integrative centers. This column poses an interesting question: might widespread engagement of the integrative model be a healing balm for the planet? Many clinicians in the field instinctively assert this would be so. The authors marshal evidence from surprising corners to reach their affirmative conclusion. Authors Aterah Z. Nusrat, MSc, DIC and Peter M. Wayne, PhD are each from the Osher Center for Integrative Medicine, Harvard Medical School and Brigham and Women's Hospital in Boston, MA where Wayne serves as Interim Center Director and Research Director and Nusrat as Program Director. Their Osher Collaborative colleague Iman Majd, MD, MS, EAMP/LAc serves as the Director of the Osher Clinical Center for Integrative Medicine at the University of Washington in Seattle, WA. This column opens the door to what merits a more expansive exploration. - John Weeks, Editor-in-Chief, JACM

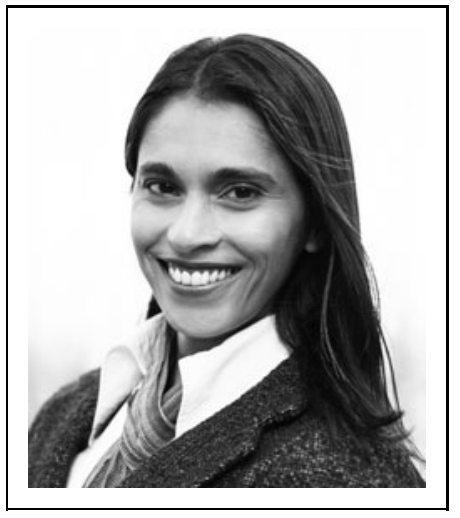

Aterah Z. Nusrat, MSc, DIC

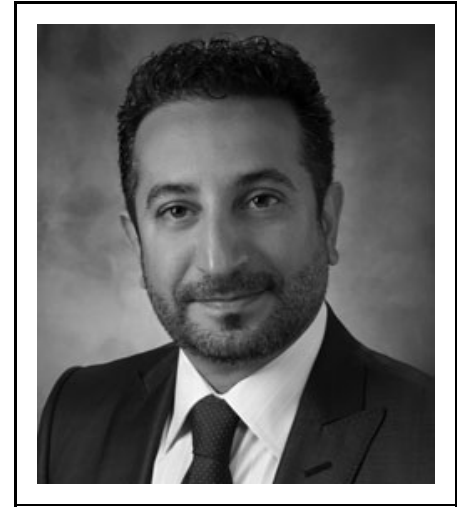

Iman Majd, MD, MS, EAMP/LAc

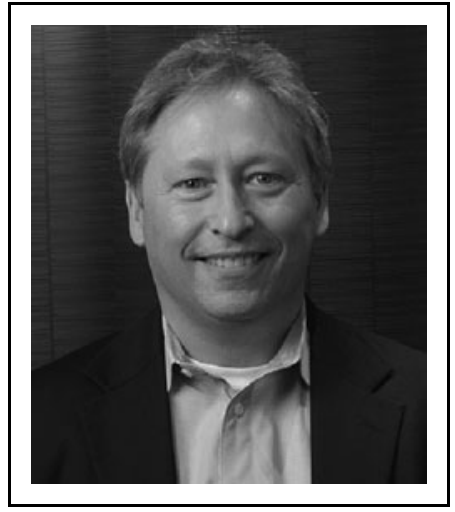

Peter M. Wayne, PhD

\section{Climate Change and Human Health}

$\mathbf{T}$ HE EVIDENCE FOR GLOBAL climate change is undeniable. Ninety-seven percent of actively publishing climate scientists agree that the Earth's climate is warming, and that warming over the past century is due, in part, to human activities. ${ }^{1}$ Equally certain is that this warming, and associated environmental changes, is already impacting human health and well-being, with biopsychosocially complex impacts on individuals and social health forecasted. ${ }^{2,3}$

${ }^{1}$ Osher Center for Integrative Medicine, Harvard Medical School and Brigham and Women's Hospital, Boston, Massachusetts.

${ }^{2}$ Osher Clinic for Integrative Medicine, University of Washington, Seattle, Washington. 
The warming climate has already increased the frequency, intensity, and duration of extreme weather events, such as heat waves, hurricanes, floods, and droughts. ${ }^{4,5}$ In 2018 alone, 16 million people worldwide were displaced due to weatherrelated disasters, resulting in physical and mental health problems associated with forced migration. ${ }^{6}$ Health impacts include: heat exhaustion; increased morbidity; incidences of asthma associated with poor air quality; illnesses transmitted by food, water, and disease-carrying vectors such as mosquitoes and ticks; and ultimately, loss of life. ${ }^{4,5,7}$ Tragically, many of these health concerns affect the most vulnerableyoung children, the elderly, pregnant women, individuals with chronic health issues, the poor and the socially isolatedexacerbating existing health disparities. ${ }^{5}$

\section{Burdens and Opportunities for Health Care Providers}

These climate change challenges expand the workload of health care providers; but they also position health care providers to become an integral force in educating the public about climate change health impacts. Salas and Hess, in their 2018 Lancet Countdown on Health and Climate Brief for the United States, state physicians are the public's most trusted source regarding information on climate change and health. ${ }^{4}$

Building upon this finding, in this brief commentary, the authors propose that the integrative medicine model is particularly well positioned to support health care professionals and health care systems in addressing the climate crisis. Integrative health emphasizes lifestyle and behavior change and a biopsychosocial approach fostering interconnections between mind, body, spirit, and social and physical environments. Fundamental strategies and premises underlying integrative medicine have the potential to directly and indirectly positively impact the environment. The authors highlight three specific strategies: An emphasis on prevention that decreases the burden on the energy-intensive health care system; provision of tools for self-regulation that might lead to "lower carbon happiness" and environmentally friendly lifestyles; and practices that have the potential to enhance prosocial and proenvironmental behavior.

\section{An Ounce of Prevention Versus Tons of Greenhouse Gases}

Getting sick is bad for individuals and the environment. With hospitals operating around the clock, energy requirements and resulting emissions are staggering. If the U.S. health care sector were its own country, it would rank 13th among the world's largest greenhouse gas emitters, between South Korea (12th) and the United Kingdom (14th); the health care sector alone is responsible for $10 \%$ of U.S. greenhouse gas emissions. ${ }^{4,8}$ Fortunately, efforts are underway to improve energy efficiency, waste management practices, and greening the supply chain to reduce the carbon footprint of health care systems. ${ }^{8}$ In this study the authors propose that a greater emphasis on integrative and preventive medicine strategies that aim to reduce the absolute number of in- and outpatients, surgical operations, emergency care visits, and use of medications is a complementary strategy for reducing the environmental impact of the health care sector while caring for patients. ${ }^{9}$
Diet change and exercise are just two examples of powerful upstream integrative and preventive medicine measures that can deliver co-benefits for people and planet. The landmark PREDIMED trial compared the benefits of a Mediterranean diet, supplemented by olive oils or nuts, versus a standard low- fat diet for patients with high cardiovascular disease risk factors. Study results support that dietary changes could reduce the rate of serious cardiovascular incidences and disease by $30 \% .^{10}$ These findings parallel those reported in many large-scale epidemiologic studies that suggest that diets with higher proportions of fruits and vegetables and healthy grains, and lower proportions of red meat, are associated with reduced risks of disease and cardiovascular events requiring energyintensive procedures, hospitalizations and long-term medical care. ${ }^{11-13}$ Of note, a shift toward plant-based diets also positively impacts the environment through agricultural sustainability, a message highlighted in the "Food in the Anthropocene: The EAT-Lancet Commission on healthy diets from sustainable food systems" lead by Harvard Scientist Walter Willet. $^{14}$

A second example of prevention for promoting health of individuals and reducing the need for energy intensive health care is the use of exercise in older adults for reducing the risk of falling. With the aging U.S. population, injury from falling is a major public health concern. Alarming statistics include one in three adults over the age of 65 years falling every year, an older adult admitted to hospital emergency rooms for a fall every $11 \mathrm{sec}$, and an adult dying from a fall every $19 \mathrm{~min} .^{15}$ In addition to individual suffering, falls result in billions of dollars of health care costs annually. ${ }^{16}$ Integrative mind-body exercises such as t'ai chi show particular promise in preventing falls. One recent study published in JAMA reported that 6 months of t'ai chi training in older adults reduces injurious fall by $50 \%$ and serious injurious falls by $75 \% .{ }^{17}$ Other studies also suggest that community-based t'ai chi fall-prevention programs are cost-effective. ${ }^{18}$ Based on reduced hospitalizations and procedures, these benefits would also extend out to the environment. Multiple studies also suggest that t'ai chi enhances exercise self-efficacy in older adults, ${ }^{19}$ which could translate into older adults walking or riding bicycles later into life, thus conceivably reducing their use of carbon emitting forms of transportation.

One forward thinking study based at the University of Wisconsin modeled potential health and environmental cobenefits of replacing short car trips with bicycle rides, using demographic and environmental data from 11 mid-west U.S. metropolitan areas. ${ }^{20}$ Knowing that short car trips are particularly detrimental for air quality and cardiorespiratory health, they evaluated the potential benefits of residents from these areas substituting half of their short car trips $(<4 \mathrm{~km})$ with bicycle-based transportation. Their findings suggest that through a combination of improved air quality from lower levels of vehicle emissions and exercise-related fitness, the occasional shift to bicycle transportation would save $\$ 3.5$ billion in health-related costs and presumably associated burdens to the health care system, with an additional $\$ 1.0$ billion in savings related to direct environmental quality. $^{20}$

Of course, diet and exercise counseling represent just two examples of preventive health strategies employed by integrative medicine practitioners that could significantly 
decrease use of the energy-intensive health care system. The authors invite others to expand on this thinking to consider other evidence-informed contributions.

\section{Self-Regulation and Lower Carbon Happiness}

It is well established that many behaviors such as shopping, eating, and traveling are often pursued not only out of necessity, but also to alleviate boredom or stress or to seek emotional gratification. $^{21,22}$ The indirect impacts of such behaviors on the environment can be quite dramatic. According to a study undertaken at Massachusetts Institute of Technology, the carbon footprint of shopping (in store or online) can range between 1.6 and $1.8 \mathrm{~kg}$ of $\mathrm{CO}_{2}$ equivalent for the purchase of a single item. ${ }^{22}$

Recognizing the potential of compulsive and materialistic behaviors to negatively impact the environment has led, in part, to the establishment of what is sometimes referred to as the "low carbon happiness" movement. ${ }^{23}$ This movement purports that people can feel healthy and rewarded without excessive consumption of high carbon goods and services. ${ }^{23}$ However, such choices, especially ones controlled by compulsion and addiction, require tools for self-regulation.

Integrative therapies that enhance mindfulness show one promising approach for self-regulation in support of lower carbon happiness. In addition to the multitude of physical and psychologic health benefits derived from these practices, ${ }^{24}$ mindfulness can strengthen one's capacity for selfregulation when experiencing negative psychologic triggers, thereby supporting the individual to make less compulsive and environmentally detrimental choices. ${ }^{25}$

Evidence to support this supposition is limited but provocative. A handful of small studies have explored the relationship between mindfulness and compulsive shopping. ${ }^{26,27}$ More robust studies have demonstrated the positive impact of introducing mindfulness therapies to manage other addictive and compulsive behaviors. ${ }^{28}$ Larimer and colleagues integrated mindfulness therapies into traditional relapse programs addressing substance abuse and drinking addictions. Results support decreased incidences of both heavy drinking and substance use at 6- and 12-month follow-ups. ${ }^{29}$

The explicit link between mindfulness and environmental impact is currently being evaluated in a visionary study led by Barrett et al. in Wisconsin. ${ }^{23}$ The randomized trial design centers on evaluating the effectiveness of an 8-week "Mindful Climate Action" curriculum that combines practices derived from mindfulness-based stress reduction programs with environmental and sustainability education. The units of observation in the study are households, and primary outcomes center on changes in family-level carbon footprints in households exposed to the training versus a waitlist control. The aims and design of this study serve as an excellent model for rigorously addressing pragmatic complex problems that bridge integrative medicine, behavior, and environmental health. $^{23}$

\section{Mindfulness Meditation and Prosocial and Environmental Behavior}

Going beyond using mindfulness therapies to improve the ability to make environmentally relevant healthier behavioral choices in the face of conflicting internal triggers, there is some very preliminary evidence that mindfulness and related contemplative practices can more fundamentally predispose individuals toward prosocial and proenvironmental behaviors. Although provocative and still poorly evidenced, this topic is worth highlighting, as it is well established that the not-sotangible issues of morality, ethics, and spirituality/religiosity greatly influence our relationships with one another, our environment, and ultimately our actions. ${ }^{30}$

Regarding prosocial behaviors, a recent systematic review evaluated therapies that included mindfulness training to see if they could enhance prosocial behavior and concluded there is mixed evidence. ${ }^{31}$ One creative study led by Condon et al. evaluated the impact of 8 weeks of either mindfulness meditation or compassion-based meditation in meditation-naive individuals. A set of conditions was created at the end of the training to test for change in compassionate behaviorspecifically, the response time for each participant in giving up their seat for a staged disabled patient (with crutches) entering a shared waiting room. The results showed an increase in prosocial compassionate behavior (shorter time to offer their seat) for those participants who undertook either mindfulnessor compassion-based meditation training, compared with a nontreatment control. ${ }^{32}$

Of relevance to the question of the link between integrative medicine and climate change is whether the enhanced altruism toward fellow human beings cultivated by mindfulness meditation extends to other species and the environment. Frameworks, such as that put forward by renowned evolutionary biologist, Edward O. Wilson in 1994, in his book "Biophilia," suggest humans are hardwired to experience a deep connection between self and nature. A recent meta-analysis of observational studies supports a positive correlation between nature connectedness and psychologic well-being. ${ }^{33}$

Further evidence for this relationship comes from experimental forest bathing research suggesting exposure to certain natural environments can impact well-being and underlying physiologic process. ${ }^{34-36}$ Observational evidence also suggests that specific and trainable dimensions of mindfulness are associated with a greater sense of feeling connected with nature-perhaps because practitioners learn to "get out of their heads" and "connect with the surrounding world.,"37

\section{Conclusions}

Health care providers have a professional responsibility to educate their patients about climate change and the personal impacts it may have on physical and mental health. Perhaps as a collateral benefit, the interventions prescribed by integrative medicine providers, including prevention and mindful self-care, may have "side effects" or "environmental co-benefits" that positively counter climate change. Along with tools for self-care, integrative therapies may also help manage the growing prevalence of "eco-anxiety" associated with climate change and environmental degredation. $^{38-40}$

Both the Lancet Report ${ }^{4}$ and the fundamental premise of integrative medicine encourage us to stop thinking of ourselves as separate passive recipients of reductive health care strategies, and instead, as active participants in an interconnected biopsychosocial global ecological system. This 
model might even empower practitioners and patients to adopt the environmentalist's adage "Think Globally, Act Locally"-where "locally" starts from within.

\section{Author Disclosure Statement}

No competing financial interests exist.

\section{Funding Information}

No funding was received for this article.

\section{References}

1. Cook J, Oreskes N, Doran PT, et al. Consensus on consensus: A synthesis of consensus estimates on humancaused global warming. IOP Sci 2016;11:1-2.

2. Watts N, Adger WN, Agnolucci P, et al. Health and climate change: Policy responses to protect public health. Lancet 2015;386:1861-1914.

3. Ebi KL, Ogden NH, Semenza JC, et al. Detecting and attributing health burdens to climate change. Environ Health Perspect 2017;125:085004.

4. Salas R, Knappenberger P, Hess J. Lancet Countdown on Health and Climate Change Brief for the United States of America. Amsterdam: Elsevier Ltd., 2018.

5. Haines A, Ebi K. The imperative for climate action to protect health. N Engl J Med 2019;380:263-273.

6. Internal Displacement Monitoring Centre. Global Report on Internal Displacement. Norway: Norwegian Refugee Council, 2019.

7. Schwerdtle P, Bowen K, McMichael C. The health impacts of climate-related migration. BMC Med 2017;16:1.

8. Eckelman MJ, Sherman J. Environmental impacts of the U.S. Health Care System and effects on public health. PLoS One 2016;11:e0157014.

9. Stahl JE, Dossett ML, LaJoie AS, et al. Relaxation response and resiliency training and its effect on healthcare resource utilization. PLoS One 2015;10:e0140212.

10. Estruch R, Ros E, Salas-Salvado J, et al. Primary prevention of cardiovascular disease with a Mediterranean diet. $\mathrm{N}$ Engl J Med 2013;368:1279-1290.

11. Micha R, Peñalvo JL, Cudhea F, et al. Association between dietary factors and mortality from heart disease, stroke, and type 2 diabetes in the United States. JAMA 2017;317:912-924.

12. Kim H, Caulfield LE, Garcia-Larsen V, et al. Plant-based diets are associated with a lower risk of incident cardiovascular disease, cardiovascular disease mortality, and allcause mortality in a general population of middle-aged adults. J Am Heart Assoc 2019;8:e012865.

13. Satija A, Bhupathiraju SN, Rimm EB, et al. Plant-based dietary patterns and incidence of type 2 diabetes in US Men and Women: Results from three prospective cohort studies. PLoS Med 2016;13:e1002039.

14. Willett W, Rockström J, Loken B, et al. Food in the Anthropocene: The EAT-Lancet Commission on healthy diets from sustainable food systems. Lancet 2019;393:447-492.

15. Verma SK, Willetts JL, Corns HL, et al. Falls and fallrelated injuries among community-dwelling adults in the United States. PLoS One 2016;11:e0150939.

16. Florence CS, Bergen G, Atherly A, et al. Medical costs of fatal and nonfatal falls in older adults. J Am Geriatr Soc 2018;66:693-698.

17. Li F, Harmer P, Fitzgerald K, et al. Effectiveness of a therapeutic Tai Ji Quan intervention vs a multimodal ex- ercise intervention to prevent falls among older adults at high risk of falling: A randomized clinical trial. JAMA Intern Med 2018;178:1301-1310.

18. Li F, Harmer P, Eckstrom E, et al. Cost-Effectiveness of a therapeutic Tai Ji Quan fall prevention intervention for older adults at high risk of falling. J Gerontol A Biol Sci Med Sci 2019;74:1504-1510.

19. Tong Y, Chai L, Lei S, et al. Effects of Tai Chi on selfefficacy: A systematic review. Evid Based Complement Alternat Med 2018;2018:1701372.

20. Grabow ML, Spak SN, Holloway T, et al. Air quality and exercise-related health benefits from reduced car travel in the midwestern United States. Environ Health Perspect 2012;120:68-76.

21. Chancellor J, Lyubomirsky S. Happiness and thrift: When (spending) less is (hedonically) more. J Consum Psychol 2011;21:131-138.

22. Weideli D. Environmental Analysis of US Online Shopping. Cambridge, MA: MIT Center for Transportation \& Logistics, Massachusetts Institute of Technology, 2013.

23. Barrett B, Grabow M, Middlecamp C, et al. Mindful climate action: Health and environmental co-benefits from mindfulness-based behavioral training. Sustainability 2016; 8:pii: 1040.

24. Gu J, Strauss C, Bond R, et al. How do mindfulness-based cognitive therapy and mindfulness-based stress reduction improve mental health and wellbeing? A systematic review and meta-analysis of mediation studies. Clin Psychol Rev 2015;37:1-12.

25. Guendelman S, Medeiros S, Rampes H. Mindfulness and emotion regulation: Insights from neurobiological, psychological, and clinical studies. Front Psychol 2017;8:220.

26. Williams AD, Grisham JR. Impulsivity, emotion regulation, and mindful attentional focus in compulsive buying. Cogn Ther Res 2012;36:451-457.

27. Benson AL, Eisenach D, Abrams L, et al. Stopping overshopping: A preliminary randomized controlled trial of group therapy for compulsive buying disorder. J Groups Addict Recov 2014;9:97-125.

28. Garland EL, Howard MO. Mindfulness-based treatment of addiction: Current state of the field and envisioning the next wave of research. Addict Sci Clin Pract 2018;13:14.

29. Bowen S, Witkiewitz K, Clifasefi SL, et al. Relative efficacy of mindfulness-based relapse prevention, standard relapse prevention, and treatment as usual for substance use disorders: A randomized clinical trial. JAMA Psychiatry 2014;71:547-556.

30. Ives CD, Kidwell J. Religion and social values for sustainability. Sustain Sci 2019;14:1355-1362.

31. Luberto CM, Shinday N, Song R, et al. A systematic review and meta-analysis of the effects of meditation on empathy, compassion, and prosocial behaviors. Mindfulness (N Y) 2018;9:708-724.

32. Condon P, Desbordes G, Miller WB, et al. meditation increases compassionate responses to suffering. Psychol Sci 2013;24:2125-2127.

33. Capaldi CA, Dopko RL, Zelenski JM. The relationship between nature connectedness and happiness: A metaanalysis. Front Psychol 2014;5:976.

34. Hansen MM, Jones R, Tocchini K. Shinrin-Yoku (forest bathing) and nature therapy: A state- of-the-art review. Int J Environ Res Public Health 2017;14:1-3.

35. Ideno Y, Hayashi K, Abe Y, et al. Blood pressure-lowering effect of Shinrin-yoku (Forest bathing): A systematic re- 
view and meta-analysis. BMC Complement Altern Med 2017;17:409.

36. Hunter MR, Gillespie BW, Chen SY. Urban nature experiences reduce stress in the context of daily life based on salivary biomarkers. Front Psychol 2019;10:722.

37. Hanley AW, Derringer SA, Hanley RT. Dispositional mindfulness may be associated with deeper connections with nature. Ecopsychology 2017;9:225-231.

38. McLaughlin KA, Berglund P, Gruber MJ, et al. Recovery from PTSD following Hurricane Katrina. Depr Anxiety 2011;28:439-446.

39. Bromet EJ, Atwoli L, Kawakami N, et al. Post-traumatic stress disorder associated with natural and human-made disasters in the World Mental Health Surveys. Psychol Med 2017;47:227-241.
40. Cunsolo A, Ellis NR. Ecological grief as a mental health response to climate change-related loss. Nat Clim Change 2018;8:275-281.

Address correspondence to:

Peter M. Wayne, PhD

Osher Center for Integrative Medicine Brigham and Women's Hospital and Harvard Medical School 900 Commonwealth Avenue, 3rd Floor Boston, MA 02215

E-mail: pwayne@partners.org 